\title{
A primary study on tensile strength stability of Mg-5Y-3Sm-0.5Sb alloy
}

\author{
Qing Zhang ${ }^{1,2, a, *}$, Jun Chen ${ }^{1,2}$ and Quan-an $\mathrm{Li}^{1,2}$ \\ ${ }^{1}$ School of Materials Science and Engineering, Henan University of Science and Technology, \\ Luoyang, China \\ ${ }^{2}$ Collaborative Innovation Center of Nonferrous Metals, Henan Province, Luoyang, China \\ a foxzq@126.com \\ *corresponding author
}

Keywords: magnesium alloy, microstructure, tensile strength, strengthening phase

Abstract. The tensile strength stability of aging hardened Mg-5Y-3Sm-0.5Sb alloy was primarily studied. The results showed that the alloy has good tensile strength at room and high temperature. The tensile strength decreases slowly from $258 \mathrm{MPa}$ at room temperature to $195 \mathrm{MPa}$ at $300{ }^{\circ} \mathrm{C}$. The tensile strength stability is superior to that of commercial heat resistant magnesium alloy WE54 developed most successfully. The formation of $\mathrm{Mg}_{24} \mathrm{Y}_{5}$ phase is observed in the alloy. The tensile strength of the alloy keeps a linear relationship with the hardness of strengthening phase $\mathrm{Mg}_{24} \mathrm{Y}_{5}$. The reason for the tensile strength stability is mainly attributed to the hardness stability of $\mathrm{Mg}_{24} \mathrm{Y}_{5}$ phase in the alloy.

\section{Introduction}

Mg-RE (rare earth elements) alloys are interesting materials since they have excellent room and high temperature mechanical properties $[1,2]$. Simultaneous addition of two or more kinds of rare earth elements from different subgroups ( $\mathrm{Y}$ subgroup, Ce subgroup) can produce good solid solution strengthening and precipitation strengthening, and enhance comprehensive mechanical properties of magnesium alloys [3]. As one of $\mathrm{Y}$ subgroup (heavy) rare earth elements, $\mathrm{Y}$ is considered to be one of the most effective rare earth elements to improve mechanical properties of magnesium alloys at high temperatures $[4,5]$. As one of Ce subgroup (light) rare earth elements, $\mathrm{Sm}$ has a unique orthorhombic structure and a high solid solubility in $\mathrm{Mg}$ [6]. Therefore, $\mathrm{Y}$ and $\mathrm{Sm}$ is an interesting combination of rare earth elements, and $\mathrm{Mg}-\mathrm{Y}-\mathrm{Sm}$ alloy is a new type of heat resistant magnesium alloy [7].

Heat resistant $\mathrm{Mg}$-Y-Sm alloys have been attached more and more importance due to their good strength and creep resistance at high temperature. They exhibit better strength and creep resistance than commercial Mg-Y-RE (WE) alloys at high temperature [8-10]. They have important application value and broad application prospect in aerospace, automotive, electronics and other fields. However, their strength stability has few been investigated. In the present work, the tensile strength stability of $\mathrm{Mg}-\mathrm{Y}-\mathrm{Sm}-\mathrm{Sb}$ alloy is primarily studied. 


\section{Experimental}

Metallic magnesium, antimony, Mg-25Y and Mg-25Sm (mass fraction, \%) master alloys were used as raw materials. All the raw materials were baked before melting. The chemical composition of tested alloy was designed as $\mathrm{Mg}-5 \mathrm{Y}-3 \mathrm{Sm}-0.5 \mathrm{Sb}$ (mass fraction, \%). The alloy was melted in an induction furnace and cast in a preheated steel mold. Then, T6 treatment including solid solution $\left(525{ }^{\circ} \mathrm{C}, 6 \mathrm{~h}\right)$ and aging treatment $\left(225^{\circ} \mathrm{C}, 12 \mathrm{~h}\right)$ was conducted for the cast alloy.

The tensile tests were carried out at a strain rate of $1 \mathrm{~mm} / \mathrm{min}$ in AG-I $250 \mathrm{kN}$ precision universal material testing machine at room temperature $\left(20^{\circ} \mathrm{C}\right)$ and high temperature $\left(200{ }^{\circ} \mathrm{C}, 250{ }^{\circ} \mathrm{C}, 300{ }^{\circ} \mathrm{C}\right)$. The gauge section size of tensile specimen is $\Phi 6 \mathrm{~mm} \times 30 \mathrm{~mm}$. The high temperature tensile tests were performed in an electric resistance furnace. The samples were held for about 5 min prior to the tensile test to reach a thermal equilibrium.

The phases were analyzed by D8 Advance X-ray diffraction meter (XRD) and MDI Jade 5.0 software. The microstructure was examined by Olympus optical microscope (OM) and JSM5610LV scanning electron microscope (SEM) with energy dispersive spectroscopy (EDS).

\section{Results}

The tensile test results show that aging hardened $\mathrm{Mg}-5 \mathrm{Y}-3 \mathrm{Sm}-0.5 \mathrm{Sb}$ alloy has good tensile strength at room and high temperature. At room temperature, the tensile strength of the alloy is only $258 \mathrm{MPa}$. With the increase of temperature, the tensile strength decreases slowly, from $243 \mathrm{MPa}$ at $200{ }^{\circ} \mathrm{C}$ to $233 \mathrm{MPa}$ at $250{ }^{\circ} \mathrm{C}$ and $195 \mathrm{MPa}$ at $300{ }^{\circ} \mathrm{C}$. It can be drawn that the tensile strength is stable and insensitive to the change of temperature. As a whole, the strength properties of the alloy are good at room temperature $\left(20^{\circ} \mathrm{C}\right)$ and high temperature $\left(200-300{ }^{\circ} \mathrm{C}\right)$. Considering applied requirement of tensile strength, the maximum applied temperature of the alloy is up to $300{ }^{\circ} \mathrm{C}$.

Among Mg-Y-RE (WE) alloys, WE54 (Mg-5.1\%Y-3.3\%RE(Nd)-0.5\%Zr) alloy is one of the heat resistant magnesium alloys developed most successfully. It has good strength properties at room and high temperature. Its tensile strength is $280 \mathrm{MPa}$ at room temperature, $240 \mathrm{MPa}$ at $200{ }^{\circ} \mathrm{C}$, $230 \mathrm{MPa}$ at $250{ }^{\circ} \mathrm{C}$ and $180 \mathrm{MPa}$ at $300{ }^{\circ} \mathrm{C}$. Its heat resistant temperature is up to $300{ }^{\circ} \mathrm{C}$ [11]. By contrast, the tensile strength of Mg-5Y-3Sm-0.5Sb alloy is lower than that of WE54 alloy at room temperature. However, the tensile strength of Mg-5Y-3Sm-0.5Sb alloy is higher than that of WE54 alloy from $200{ }^{\circ} \mathrm{C}$ to $300{ }^{\circ} \mathrm{C}$. As a result, the tensile strength of Mg-5Y-3Sm-0.5Sb alloy is more stable from room temperature to $300{ }^{\circ} \mathrm{C}$. Its tensile strength stability is superior to that of heat resistant magnesium alloy WE54 developed most successfully. It is very helpful to enhancing the safety and reliability of magnesium alloy components working under high temperature. The reason for the tensile strength stability of the alloy requires further research.

Figure 1 shows the microstructure and XRD pattern of aging hardened $\mathrm{Mg}-5 \mathrm{Y}-3 \mathrm{Sm}-0.5 \mathrm{Sb}$ alloy. It can be seen that the microstructure of the alloy consists of white matrix and black particles. According to the relative phase diagrams and XRD pattern, there are $\mathrm{Mg}$ matrix and $\operatorname{Mg}_{24} \mathrm{Y}_{5}$, $\mathrm{Mg}_{41} \mathrm{Sm}_{5}, \mathrm{Mg}_{3} \mathrm{Sb}_{2}$ phases in the alloy. It can also be seen that the microstructure of the alloy has two outstanding features: (1) the grain is uniform but its average size is not very small; (2) the particle phases distributes dispersedly in the alloy but some of them are not very small. 
a

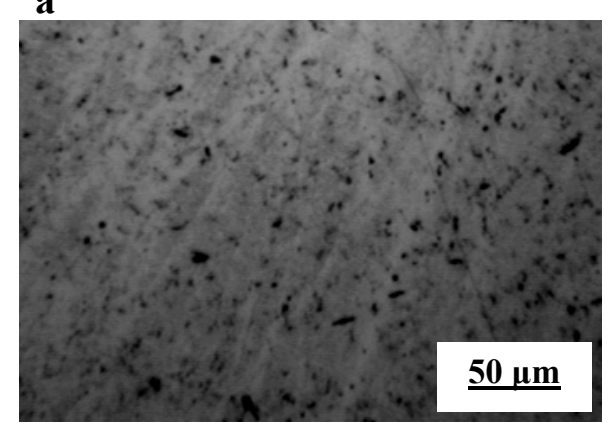

b

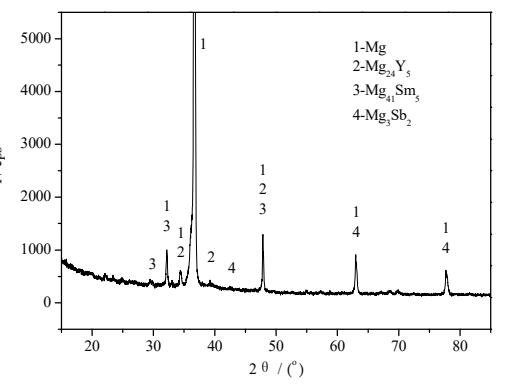

Figure 1 Microstructure (a) and XRD pattern (b) of Mg-5Y-3Sm-0.5Sb alloy.

Figure 2 shows SEM image of the microstructure and EDS analysis results of particle A in aging hardened Mg-5Y-3Sm-0.5Sb alloy. It can be seen that the particle phase consists of four elements $\mathrm{Mg}, \mathrm{Y}, \mathrm{Sm}$ and $\mathrm{Sb}$. The content of $\mathrm{Mg}$ and $\mathrm{Y}$ is high but the content of Sm and Sb is very low. Considering the XRD pattern in Figure 1, the formation of $\mathrm{Mg}_{24} \mathrm{Y}_{5}$ phase is detected in the alloy. It can be drawn that the particle phase should be $\mathrm{Mg}_{24} \mathrm{Y}_{5}$. And the existence of $\mathrm{Sm}$ and $\mathrm{Sb}$ in the particle phase can be explained to be the dissolving of part $\mathrm{Sm}$ and $\mathrm{Sb}$ in $\mathrm{Mg}_{24} \mathrm{Y}_{5}$ phase. As a result, the stability of strengthening phase $\mathrm{Mg}_{24} \mathrm{Y}_{5}$ is enhanced with the dissolving of Sm and $\mathrm{Sb}$.
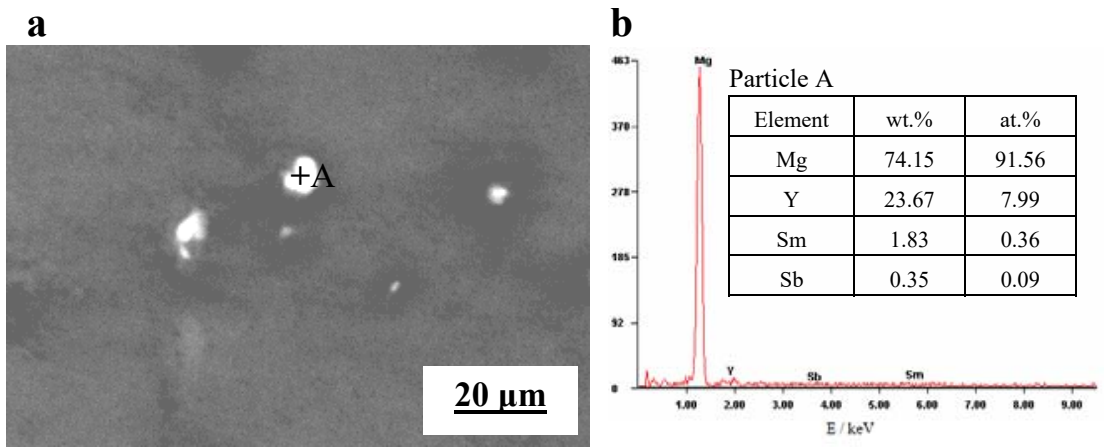

Figure 2 SEM image showing microstructure (a) and EDS analysis results of particle A (b)

$$
\text { in } \mathrm{Mg}-5 \mathrm{Y}-3 \mathrm{Sm}-0.5 \mathrm{Sb} \text { alloy. }
$$

At high temperature, the strength of magnesium alloy depends on strengthening phases at grain boundaries. Considering the microhardness of phases in magnesium alloy (see Table 1)[12], the thermal stability of $\mathrm{Mg}_{24} \mathrm{Y}_{5}$ phase in $\mathrm{Mg}-\mathrm{Y}$ alloy is much higher than that of $\mathrm{Mg}_{17} \mathrm{Al}_{12}$ phase in $\mathrm{Mg}$ Al alloy. The thermal stability of strengthening phase determines the heat resistant temperature of the alloy and its position in heat resistant magnesium alloys. Judged from that the hardness drop of strengthening phase is less than $20 \%$, the heat resistant temperature of $\mathrm{Mg}$-Al alloy does not exceed $200{ }^{\circ} \mathrm{C}$. It is consistent with the previous research results. The hardness of $\mathrm{Mg}_{24} \mathrm{Y}_{5}$ decreases slowly with the increase of temperature, from $218 \mathrm{HV}$ at $20^{\circ} \mathrm{C}$ to $173 \mathrm{HV}$ at $300{ }^{\circ} \mathrm{C}$, and the drop is a little more than $20 \%$. So Mg-Y-RE alloy (such as WE54) has good heat resistance and its maximum applied temperature is up to $300^{\circ} \mathrm{C}$.

Table 1 Microhardness of some phases in magnesium alloy.

\begin{tabular}{|c|c|c|c|c|}
\hline \multirow{2}{*}{ Phase } & \multicolumn{4}{|c|}{ Microhardness / HV } \\
\cline { 2 - 5 } & $20{ }^{\circ} \mathrm{C}$ & $200{ }^{\circ} \mathrm{C}$ & $250{ }^{\circ} \mathrm{C}$ & $300{ }^{\circ} \mathrm{C}$ \\
\hline $\mathrm{Mg}_{24} \mathrm{Y}_{5}$ & 218 & 201 & 196 & 173 \\
\hline $\mathrm{Mg}_{17} \mathrm{Al}_{12}$ & 183 & 158 & 125 & 84 \\
\hline
\end{tabular}

In order to find out the reason for strength stability of aging hardened $\mathrm{Mg}-5 \mathrm{Y}-3 \mathrm{Sm}-0.5 \mathrm{Sb}$ alloy, the relationship between tensile strength of Mg-5Y-3Sm- $0.5 \mathrm{Sb}$ alloy and microhardness of $\mathrm{Mg}_{24} \mathrm{Y}_{5}$ 
phase is plot and fitted linearly (see Figure 3). It can be seen that the tensile strength keeps a linear relationship with the microhardness of $\mathrm{Mg}_{24} \mathrm{Y}_{5}$ phase. So the reason for tensile strength stability is mainly attributed to the hardness stability of strengthening phase $\mathrm{Mg}_{24} \mathrm{Y}_{5}$. Of course, $\mathrm{Sm}$ and $\mathrm{Sb}$ also play an important role in the alloy. The dissolved $\mathrm{Sm}$ and $\mathrm{Sb}$ enhance the thermal stability and thereby the dispersion strengthening effect of $\mathrm{Mg}_{24} \mathrm{Y}_{5}$ phase in the alloy. Therefore, $\mathrm{Mg}_{24} \mathrm{Y}_{5}$ phase keeps high hardness at high temperature and still acts as a bar to dislocation movement and boundary sliding and therefore improves the strength properties of the alloy at high temperature. In addition, strengthening phases $\mathrm{Mg}_{41} \mathrm{Sm}_{5}$ and $\mathrm{Mg}_{3} \mathrm{Sb}_{2}$ in the alloy are helpful to enhance the strength stability to some extent.

\section{Conclusions}

In this work, aging hardened $\mathrm{Mg}-5 \mathrm{Y}-3 \mathrm{Sm}-0.5 \mathrm{Sb}$ alloy has good tensile strength at room and high temperature. With the increase of temperature from room temperature to $300{ }^{\circ} \mathrm{C}$, the tensile strength of the alloy decreases slowly from $258 \mathrm{MPa}$ to $195 \mathrm{MPa}$. The tensile strength stability of the alloy is superior to that of heat resistant magnesium alloy WE54 developed most successfully. The reason for the tensile strength stability is mainly attributed to the hardness stability of strengthening phase $\mathrm{Mg}_{24} \mathrm{Y}_{5}$ in the alloy.

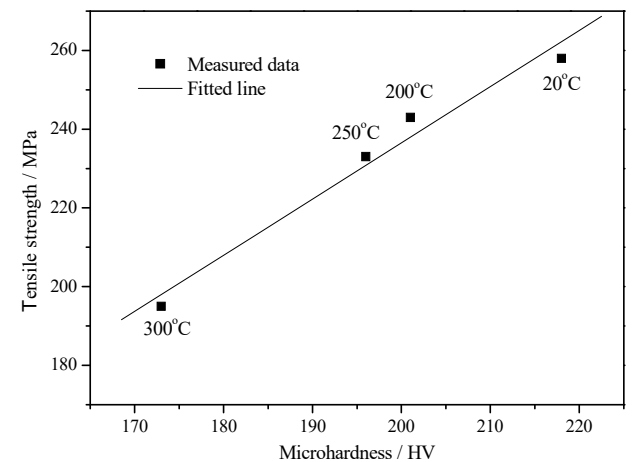

Figure 3 Relationship between tensile strength of $\mathrm{Mg}-5 \mathrm{Y}-3 \mathrm{Sm}-0.5 \mathrm{Sb}$ alloy and microhardness of $\mathrm{Mg}_{24} \mathrm{Y}_{5}$ phase.

\section{Acknowledgements}

This work is financially supported by the National Natural Science Foundation of China (NSFCHenan Joint Fund of Personnel Training, Grant No. U1404501).

\section{References}

[1] Mayumi S, Hiroyuki S, Kouich M, Hiroshi O. Creep deformation behavior and dislocation substructures of Mg-Y binary alloys [J]. Materials Science and Engineering A, 2001, 319-321: 751-755.

[2] Mayumi S, Tsuyoshi K, Junichi K, Kouichi M. Effects of zinc on creep strength and deformation substructures in Mg-Y alloy [J]. Materials Science and Engineering A, 2004, 387-389: 706-709.

[3] Rokhlin L L, Dobatkina T V, Nikitina N I. Constitution and properties of the ternary magnesium alloys containing two rare-earth metals of different subgroups [J]. Materials Science Forum, 2003, 419-422: 291-296.

[4] Zhang Jinghuai, Tang Dingxiang, Zhang Hongjie, Wang Limin, Wang Jun, Meng Jian. Effect and application of rare earth element in magnesium alloys[J]. Chinese Journal of Rare Metals, 2008, 32(5): 659-667.

[5] Deng Yonghe. Research progress and development trend in Mg-RE Alloys [J]. Chinese Rare Earths, 2009, 30(1): 76-79. 
[6] Li Kejie, Li Quan-an, Jing Xiaotian, Chen Jun, Zhang Xingyuan, Zhang Qing. Effects of Sm addition on microstructure and mechanical properties of Mg-6Al-0.6Zn alloy [J]. Scripta Materialia, 2009, 60(12): 1101-1104.

[7] Ding Wenjiang. Magnesium alloy science and technology [M]. Beijing: Science Press, 2007: 112-116.

[8] Li Daquan, Wang Qudong, Ding Wenjiang. Effects of heat treatments on microstructure and mechanical properties of Mg-4Y-4Sm-0.5Zr alloy [J]. Materials Science and Engineering A, 2007, 448: 165-170.

[9] Wang Qudong, Li Daquan, Suéry M, Donnadieu P, Ding Wenjiang. Microstructure and creep behavior of the extruded Mg-4Y-4Sm-0.5Zr alloy [J]. Materials Science and Engineering A, 2009, 516: 189-192.

[10] Zhang Qing, Li Quan-an, Chen Jun, Zhang Xingyuan. Microstructure and tensile strength of Mg-5Y-3Sm0.8Ca-(0.1 0.8)Sb alloy [J]. Journal of the Chinese Society of Rare Earths, 2015, 33(6): 718-723.

[11] Zhang Xinming, Peng Zhuokai, Chen Jianmei, Deng Yunlai. Heat-resistant magnesium alloys and their development [J]. The Chinese Journal of Nonferrous Metals, 2004, 14(9): 1443-1450.

[12] Chen Zhenhua. Heat resistant magnesium alloy[M]. Beijing: Chemical Industry Press, 2007: 203-206. 